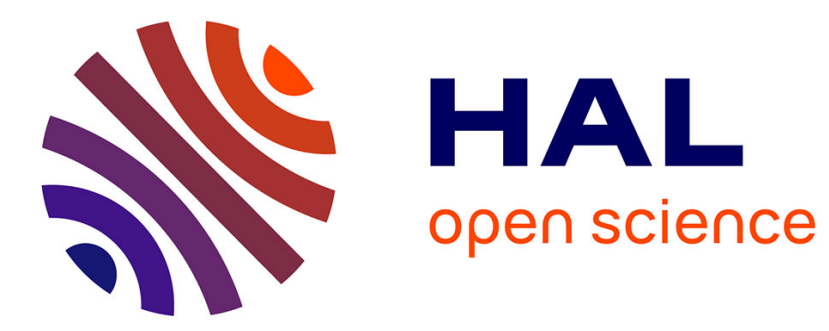

\title{
Resistivity annealing properties of aluminium thin films after ion implantation at liquid helium temperatures
}

\author{
A.M. Lamoise, J. Chaumont, Frédéric Meunier, H. Bernas
}

\section{To cite this version:}

A.M. Lamoise, J. Chaumont, Frédéric Meunier, H. Bernas. Resistivity annealing properties of aluminium thin films after ion implantation at liquid helium temperatures. Journal de Physique Lettres, 1975, 36 (12), pp.305-308. 10.1051/jphyslet:019750036012030500 . jpa-00231215

\section{HAL Id: jpa-00231215 https://hal.science/jpa-00231215}

Submitted on 1 Jan 1975

HAL is a multi-disciplinary open access archive for the deposit and dissemination of scientific research documents, whether they are published or not. The documents may come from teaching and research institutions in France or abroad, or from public or private research centers.
L'archive ouverte pluridisciplinaire HAL, est destinée au dépôt et à la diffusion de documents scientifiques de niveau recherche, publiés ou non, émanant des établissements d'enseignement et de recherche français ou étrangers, des laboratoires publics ou privés. 


\title{
RESISTIVITY ANNEALING PROPERTIES OF ALUMINIUM THIN FILMS AFTER ION IMPLANTATION AT LIQUID HELIUM TEMPERATURES (*) $^{*}$
}

\author{
A. M. LAMOISE and J. CHAUMONT \\ Laboratoire René Bernas du \\ Centre de Spectrométrie Nucléaire et Spectrométrie de Masse, \\ 91406 Orsay, France \\ F. MEUNIER \\ Laboratoire de Physique des Solides $(* *)$ \\ Université Paris-Sud, 91406 Orsay, France
}

H. BERNAS

Institut de Physique Nucléaire, Université Paris-Sud, 91406 Orsay, France

(Reçu le 9 juillet 1975, accepté le 26 septembre 1975)

\begin{abstract}
Résumé. - Nous présentons les premiers résultats de recuit de résistivité pour des couches minces d'aluminium après implantation d'ions $\mathrm{Al}, \mathrm{H}$ et $\mathrm{O}$ à des températures inférieures à $6 \mathrm{~K}$. La courbe de recuit après implantation d'ions $\mathrm{Al}$ est semblable à celle obtenue après irradiation aux neutrons. L'implantation d'ions $\mathrm{H}$ à faible dose fait apparaître deux pics très marqués au stade $\mathrm{I}$ du recuit. Après implantation de fortes doses d'hydrogène, la courbe de recuit indique la possibilité d'un ordre des ions $\mathrm{H}$ ou bien d'une transformation de phase.
\end{abstract}

\begin{abstract}
We present the first resistivity annealing curves of $\mathrm{Al}$ after implantation of $\mathrm{Al}-\mathrm{H}-\mathrm{H}$, and O-ions at liquid helium temperatures. The Al-implantation produces a curve resembling that of neutron-irradiated $\mathrm{Al}$; low-dose $\mathrm{H}$ - implantation results in two strongly enhanced stage I recovery peaks, while high-dose $\mathrm{H}$ - implantation annealing results suggest that $\mathrm{H}$-ordering or a phase transformation takes place.
\end{abstract}

Although ion implantation in metals is a welldeveloped technique [1], the standard techniques of radiation damage physics have not yet all found their application in this field. This is of course due to the relatively low implantation energies : typical range profiles rarely go beyond $\sim 1000 \AA$ so that samples must be made of thin films in order to use techniques such as resistivity measurements with a reasonable signal-to-noise ratio. Moreover, it is often necessary to operate at low temperatures and implantation conditions are in general rather unfavourable for such experiments. Another prejudice against resistivity measurements on implanted metal thin films was that since the film thickness is of the order of the conduction electron mean free path, the resistivity change due to radiation-induced defect annealing would be washed out by the size effect of the film.

$\left({ }^{*}\right)$ Work partially supported by D.G.R.S.T. Project 738 . (**) Associé au C.N.R.S.
We have set up a liquid He cryostat on the Orsay ion implantor, and have equipped it so that reasonably accurate resistivity annealing experiments can be carried out on implanted metallic thin films. In this paper, we present our first results on ion-implanted $\mathrm{Al}$ films. In order to determine the effect of ion-induced radiation damage alone, $\mathrm{Al}$ was implanted into $\mathrm{Al}$ at fairly low doses. $\mathrm{H}$ - implanted $\mathrm{Al}$ (again at low dose) provided information on the annealing spectrum of interstitials. Because of their interesting superconducting properties [2] the resistivity annealing of the concentrated Al-H systems was also measured. Finally, in a search for chemical effects related to oxide formation, we have studied the resistivity annealing of concentrated $\mathrm{O}$ - implanted $\mathrm{Al}$. The results on the various samples are strikingly different, and indicate that resistivity annealing experiments can be quite useful in understanding the properties of implanted metals and alloys.

The experimental arrangement and film preparation 
technique are briefly summarized in [2], and will be described in detail elsewhere. The aluminium films (typically $10 \times 0.3 \mathrm{~mm}^{2}$, thickness $1300-1650 \AA$ ) were prepared by $\mathrm{Al}$ evaporation on crystalline quartz substrates in a standard bell-jar vacuum. Their resistivity ratio $\rho(300 \mathrm{~K}) / \rho(4.2 \mathrm{~K})$ was about 2.7 .

Resistivities were measured using a standard fourpoint probe technique, and size and impurity effects were normalized out by simultaneous measurement of the implanted sample and of an identical film mounted in the cryostat at the same time, but shielded from the ion beam. Al- implantation was carried out at a single energy (100 keV-Al). Using standard slowingdown theory [3], the range and range distribution are estimated at $1200 \AA$ and $400 \AA$, respectively. For the $1500 \AA$ - thick film used in this case, this produces a sample which has been implanted throughout. The measured resistivity is of course an average, since the defect depth distribution is approximately gaussian. We also find that the resistivity increase is not proportional to the dose. Although this prevents precise absolute measurements, it still allows better than order-of-magnitude values of the radiation induced resistivity increment to be obtained, as well as accurate relative resistivity annealing measurements. For the lightest ions (especially $\mathbf{H}$ and $\mathrm{D}$ ), the range parameters are subject to larger uncertainties and the range distributions are relatively narrower [4]. Hence (i) in order to obtain more uniform samples, two or three implantations (at different energies) had to be carried out, and (ii) an approximate total absolute resistivity increase was deduced from the values measured after the last of the successive implantations. For example, in the case of a typical $\mathrm{H}$ implantation the measured film resistance increased from $1.53 \Omega$ to $19.30 \Omega$ after a $10 \mathrm{keV} / \mathrm{amu}$ implantation at a dose of $10^{18}$ at. $\mathrm{cm}^{-2}$, then to $31.5 \Omega$ after a $5 \mathrm{keV} / \mathrm{amu}$ implantation at a dose of $7 \times 10^{17}$ at. $\mathrm{cm}^{-2}$, and finally to $38.7 \Omega$ after a $2.5 \mathrm{keV} / \mathrm{amu}$ implantation at a dose of $10^{17}$ at. $\mathrm{cm}^{-2}\left({ }^{1}\right)$. (Dose rates ranged from $8 \times 10^{15}$ at. $\mathrm{cm}^{-2} \cdot \mathrm{s}^{-1}$ to $2 \times 10^{15}$ at. $\mathrm{cm}^{-2} \cdot \mathrm{s}^{-1}$.)

The resistivity annealing curve obtained on Alimplanted $\mathrm{Al}$ at a relatively low dose is presented in figure $1 a$ and compared to the result previously obtained by Burger et al. [5] on neutron-irradiated bulk Al. It is readily seen that the general shape of the annealing spectra are quite similar. The annealing peaks at $19 \mathrm{~K}$ (usually ascribed to close-pair annealing) and $\sim 230 \mathrm{~K}$ (stage III) are absent in the ion-implanted sample, while the detailed structure of stage II annealing differs somewhat. The overall similarity is comforting, as neutron- and ion- irradiation are expected to produce similar damage : this indicates that film size effects do not dominate the annealing process, a point that is reinforced by the fact that the

( $\left.{ }^{1}\right)$ These values may be accounted for if the tail of the implantation profile extends out to the surface.

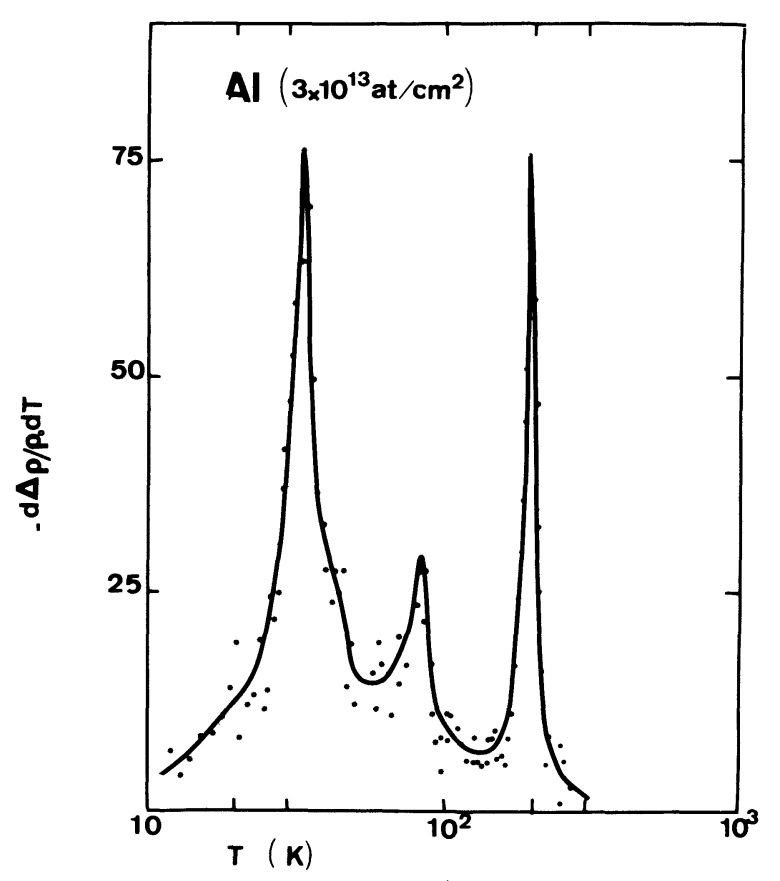

a)

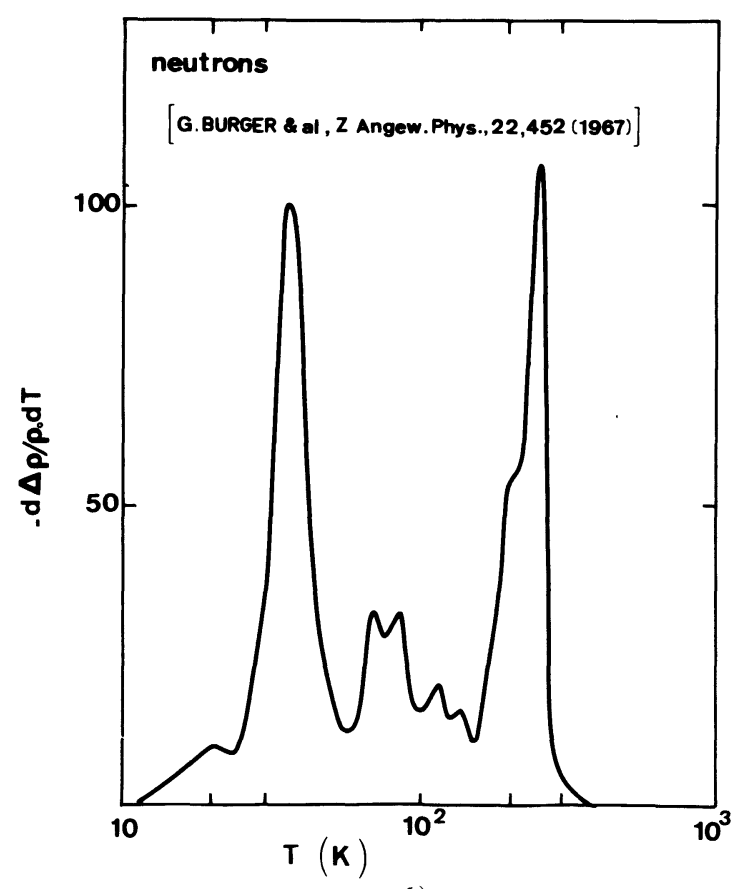

b)

FIG. 1. - a) Differential resistivity annealing curve for Alimplanted $\mathrm{Al}$, at a dose of $3 \times 10^{13}$ at. $\mathrm{cm}^{-2}$ (dose rate of $8 \times 10^{14}$ at. $\left.\mathrm{cm}^{-2} \cdot \mathrm{s}^{-1}\right)$. The film resistivity was $\sim 5 \mu \Omega . \mathrm{cm}$ before implantation and $7.5 \mu \Omega$.cm after implantation. b) Differential resistivity annealing curve for neutron-irradiated bulk $\mathrm{Al}$ according to reference [5].

same annealing spectrum was found after Al- implantation in a $450 \AA$ - thick film. The absence of the peak at $230 \mathrm{~K}$ may yield some information on the concentration of energy deposition (hence of defect creation) due to the incoming ion : if the damage density is high enough di- and tri- vacancy formation 
are more probable 'than monovacancy formation, a process that would lead to a stronger annealing in the first part of stage III (if one assumes that all of stage III is due to vacancy annealing). The dose dependence of the relative resistivity increase is shown in figure 2 : the incremental change in the resistivity shows an inverse-dose dependence over nearly three orders of magnitude.

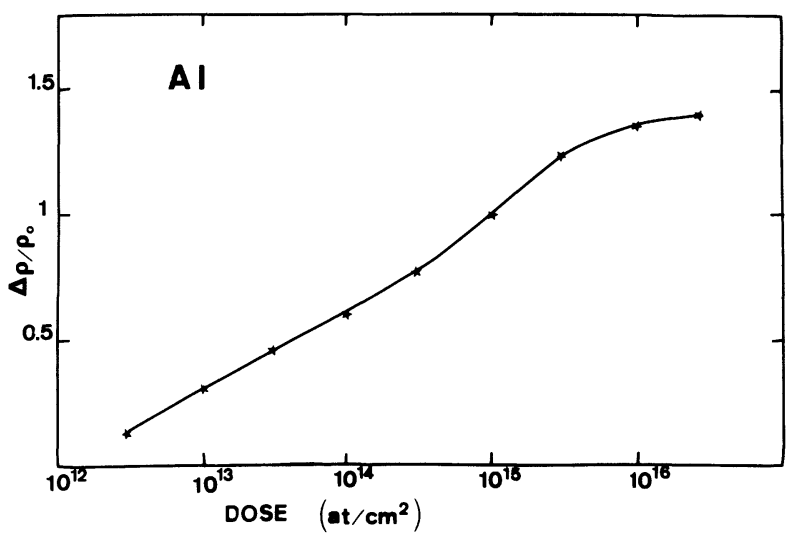

FIG. 2. - Dose dependence of relative resistivity increment for Alimplanted Al (implantation energy $100 \mathrm{keV}$; film thickness $1300 \AA$ ).

The effect of interstitial hydrogen is strikingly demonstrated in figure $3 a$; when compared to figure $1 a$ a two-fold increase is found in stage I annealing and the stage III annealing amplitude is correspondingly reduced. The reappearance of a large close-pair annealing peak at $19 \mathrm{~K}$ can be accounted for by the lower deposited energy concentration produced by H- implantation. At high, fairly uniform concentrations, the annealing spectrum shifts considerably toward higher energies. We have made no attempt to interpret the observed peaks, but it is quite clear that at least some of them (see dotted peak at $200 \mathrm{~K}$ in figure $3 b$ and peak at $300 \mathrm{~K}$ in figure $3 c$ ) are far too sharp to be accounted for by the migration of a simple defect : $\mathrm{H}$ - disordering and/or phase transformations could possibly occur, accompanied or followed by bubble formation as evidenced by optical microscopy on room-temperature annealed samples.

The annealing spectrum of high-dose $\mathrm{O}$ - implanted $\mathrm{Al}$ (Fig. 4) is again quite different. The results are too preliminary to allow any analysis, but they do suggest that resistivity annealing experiments may be an interesting method for the study of oxide formation after low temperature implantation. Further work is obviously needed to obtain quantitative information, but a number of interesting features have already appeared in these preliminary resistivity annealing experiments on low-temperature implanted films.
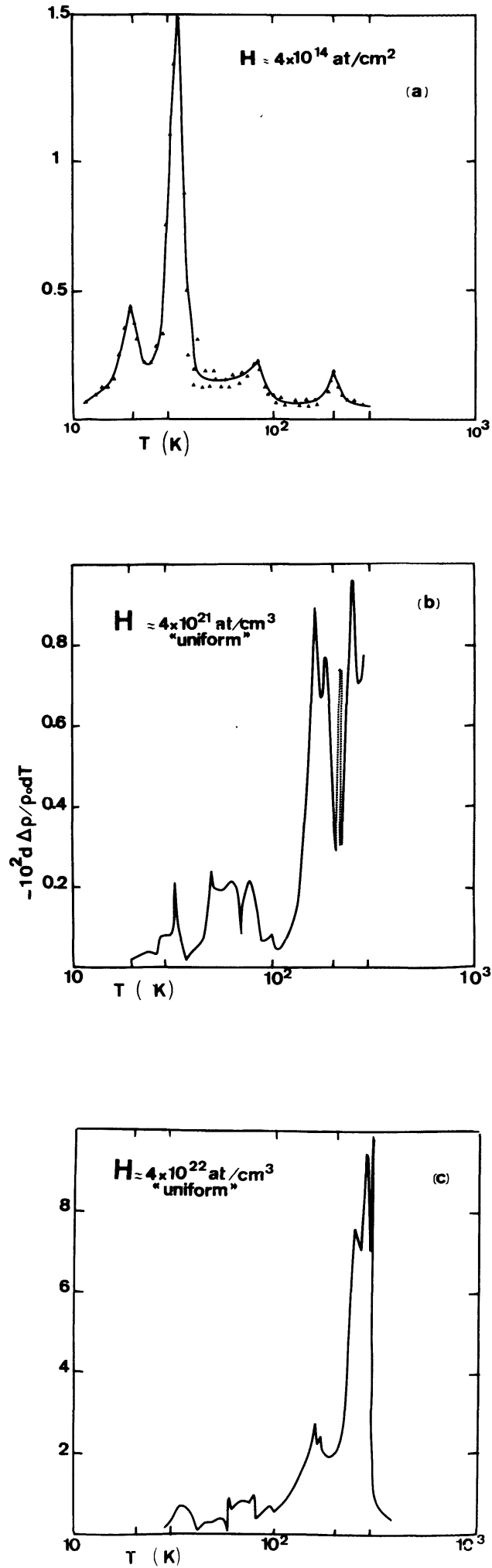

FIG. 3. - Differential resistivity annealing curves for $\mathrm{H}$ - implanted $\mathrm{Al}$ at : a) low dose, for which a $15 \mathrm{keV} / \mathrm{amu}$ implantation produced the same total resistivity change as $\mathrm{Al}$ in figure $1 a$ ); $b$ ) high total dose and fairly uniform concentration obtained by implanting at 10,5 and $2.5 \mathrm{keV} / \mathrm{amu} ; c$ ) same as $b$ ) with concentration multiplied by 10 . Dose rates ranged from $8 \times 10^{15}$ at. $\mathrm{cm}^{-2} \cdot \mathrm{s}^{-1}$ to $2 \times 10^{15}$ at. $\mathrm{cm}^{-2} \cdot \mathrm{s}^{-1}$. Note : Due to temperature limitations, curve $b$ ) could not be followed above $330 \mathrm{~K}$. However, at that temperature, more than $60 \%$ of the resistivity increase had been annealed. 


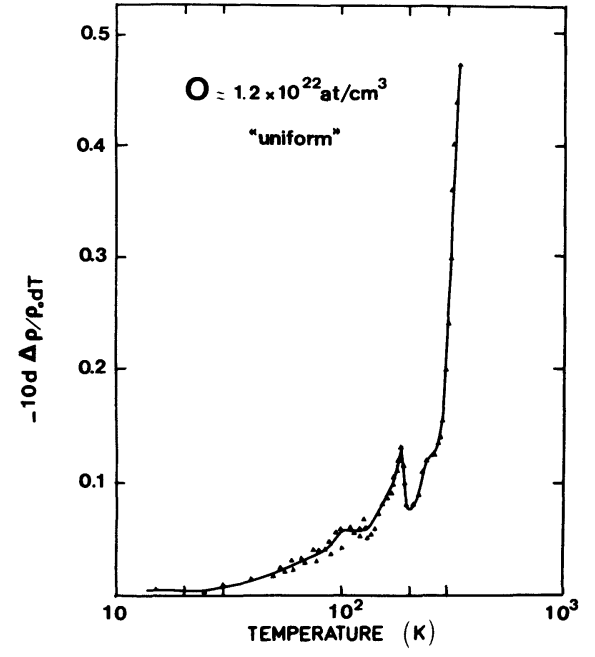

Acknowledgments. - We wish to acknowledge Dr. P. Lucasson for useful discussions and F. Lalu and M. Salomé as well as S. Buhler and the LowTemperature Group of Institut de Physique Nucléaire, Orsay, for their help in designing, building and operating the cryostat.

\section{References}

[1] Ion Implantation in Metals, ed. S. T. Picraux, E. P. Eer Nisse and F. Vook (Plenum Press, N. Y.) 1974.

[2] Lamoise, A. M., Chaumont, J., Meunier, F. and Bernas, H., to be published.

[3] Lindhard, J., Scharff, M. and SchiфTt, H., Mat. Fys. Medd. Dan. Vid. Selsk. 33 (1963) 14.
[4] Schiфтт, H., Mat. Fys. Medd. Dan. Vid. Selsk. 35 (1966) 9. [5] BuRger, G., IsebeCK, K., VölKL, J., Schilling, W. and Wenzl, H., Z. Angew. Phys. 22 (1967) 452.

[6] Corbett, J. W., Smith, R. B. and WALKer, R. M., Phys. Rev. 114 (1959) 1460. 